Undas Vol 12. , Nomor 2, Desember $2016: 67--78$

\title{
MEMAKNAI LEGENDA NISAN BERLUMUR DARAH (ANALISIS STRUKTRURALISME LEVI-STRAUSS)
}

\author{
" The Meaning of Legenda Nisan Berlumur Darah" \\ (Structurucralism Levi-Strauss)
}

\author{
Sri Wahyu Nengsih \\ Balai Bahasa Kalimantan Selatan \\ Jalan Jenderal Ahmad Yani Km 32,2, Loktabat, Banjarbaru 70712 Kalimantan Selatan \\ Telepon (0511) 4772641, Pos-el: Sriwahyu81@rocketmail.com
}

\begin{abstract}
Abstrak: Legenda Nisan Berlumur Darah sebagai sebuah legenda menyimpan simbol-simbol yang dapat dimaknai secara tidak langsung mengenai prinsip hidup masyarakat Martapura. Masyarakat Martapura yang terkenal relegius mendasari setiap keputusan penting dalam hidupnya berdasarkan aturan Islam. Penelitian ini membahas tentang "memaknai legenda Nisan Berlumur Darah". Tujuan penelitian ini untuk mendeskripsikan makna Legenda Nisan Berlumur Darah. Penelitian ini merupakan penelitian kualitatif dengan menggunakan metode deskriptif. Teknik pengumpulan data yang digunakan adalah studi pustaka. Hasil penelitian ini akan diketahui tentang "Legenda Nisan Berlumur Darah" sebagai sebuah legenda yang menyimpan simbol-simbol yang dapat dimaknai secara tidak langsung mengenai prinsip hidup masyarakat Martapura yang berpegang pada aturan agama.
\end{abstract}

Kata kunci: Mitos, simbol, struktruralisme

Abstract: Nisan Berlumur Darah as a legend save symbols which can be interpreted indirectly on the principle of people's lives Martapura. Martapura famous society relegius underlie every important decision in his life by the rules of Islam. This study discusses "The meaning of Legenda Nisan Berlumur Darah". The purpose of this study is to describe the meaning of Legenda Nisan Berlumur Darah. This study is a qualitative study using descriptive methods. Data collection techniques used is literature. The results of this study will be known about the picture of diverse cultural traditions and principles of life that exist in Banjar community in this case the Martapura.

Key words: Myth, symbols, structruralism

\section{PENDAHULUAN}

Masyarakat Kalimantan Selatan memiliki ragam kebudayaan kolektif yang diwariskan turun temurun secara tradisional. Ragam kebudayaan kolektif tersebut diantaranya terdapat dalam cerita rakyat Kalimantan Selatan. Melalui cerita rakyat dapat diketahui berbagai simbol-simbol kebudayaan dalam nilai-nilai kehidupan masyarakat Banjar.

Cerita rakyat Kalimantan Selatan diantaranya yaitu, "legenda Nisan Berlumur Darah". "Legenda Nisan Berlumur Darah" berasal dari daerah kabupaten Banjar, tepatnya kota Martapura. Melalui legenda ini, berbagai nilai-nilai kehidupan dalam kebudayaan Banjar tergambar. Kehidupan agamis dari kota santri 
digambarkan melalui prinsip islami hidup tokoh. Selain itu, tradisi kebudayaan Banjar dalam perkawinan secara tidak langsung diceritakan dalam legenda ini.

"Legenda Nisan Berlumur Darah" menceritakan sebuah percintaan dua orang muda mudi yang kandas. Kandasnya cinta muda mudi ini karena latar belakang sosial mereka yang berbeda sehingga tidak mendapat restu orang tua. Sang perempuan yang berasal dari keluarga kaya raya terpaksa mengorbankan rasa cintanya demi baktinya kepada orang tuanya. Legenda ini berakhir tragis, sang perempuan tewas tertusuk kayu ulin di makam lelaki yang sangat dicintainya.

Legenda merupakan jenis cerita prosa yang dipercaya kebenarannya oleh masyarakat pendukungnya, tetapi kejadiannya ditempatkan pada dunia seperti yang dikenal sekarang, dalam periode waktu yang belum begitu lampau. Pelaku legenda biasanya manusia dan bersifat lebih sekuler (Taum, 2011:67-68). Legenda biasanya dihubungkan dengan sejarah yang terjadi di suatu tempat dan ditambah unsur angan-angan kolektif. Legenda mirip dengan mitos, tetapi legenda tidak dianggap suci.

Kekayaan nilai-nilai kehidupan yang menggambarkan beragam kebudayaan kolektif terdapat dalam cerita rakyat. Itulah sebabnya cerita rakyat dikatakan sebagai aset berharga bangsa. Cerita rakyat merupakan warisan luhur generasi terdahulu kepada generasi selanjutnya. Keberadaan cerita rakyat seharusnya tetap bertahan dalam kehidupan masyarakatnya. Derasnya arus modernisasi seharusnya tidak membuat cerita rakyat hilang dalam tatanan kehidupan masyarakatnya. Oleh karena itu, cerita rakyat perlu untuk dimaknai berbagai simbol-simbol di dalamnya.

Berdasarkan hal tersebut, peneliti merasa tertarik untuk menjadikan cerita rakyat Banjar ini sebagai objek penelitian, khususnya "Legenda Nisan Berlumur Darah" untuk memaknainya. Penelitian mengenai memaknai suatu cerita rakyat sudah pernah dilakukan Dhanu Priyo Prabowo (2015) yang berjudul "Makna Mitos Asal Nama Kota Banyuwangi: Sebuah Analisis Strukturalisme Levi-Strauss". Hasil penelitian tersebut membahas Makna Mitos yang terdapat pada cerita asal nama kota Banyuwangi. Namun sepengetahuan peneliti, penelitian mengenai "Memaknai Legenda Nisan Berlumur Darah" ini belum pernah dilakukan. Berbeda dengan penelitian sebelumnya, penelitian ini membahas Mitos "Legenda Nisan Berlumur Darah yang menyimpan simbol-simbol yang dapat dimaknai secara tidak langsung mengenai prinsip hidup masyarakat Martapura yang berpegang pada aturan agama.

Penelitian ini membahas masalah makna "Legenda Nisan Berlumur Darah". Tujuan dari penelitian ini untuk mendeskripsikan makna Legenda Nisan Berlumur Darah.

\section{KERANGKA TEORI}

Taum (2011:11) mengatakan bahwa sastra lisan mengungkapkan kesadaran kolektif masyarakat lokal mengenai kehidupan, adat istiadat, dan keyakinan-keyakinan mereka. Sastra lisan termasuk didalamnya adalah 
legenda atau mitos sebagai bagian dari cerita rakyat.

Legenda dikatakan seperti mitos. Legenda merupakan jenis cerita prosa yang seperti mitos dipercaya kebenarannya oleh masyarakat pendukungnya, tetapi kejadiannya ditempatkan pada dunia seperti yang dikenal sekarang, dalam periode waktu yang belum begitu lampau. Pelaku legenda biasanya manusia dan bersifat lebih sekuler (Taum, 2011:67-68).

Subtansi legenda tak semata-mata pada gaya (style), melainkan pada cerita yang ditampilkan. Secara singkat, legenda memiliki ciri khas antara lain sebagai berikut: (1) jika legenda memiliki makna, maka letaknya bukan pada elemen-elemen terisolasi di dalam komposisi sebuah legenda, melainkan pada suatu cara yang mengkombinasikan elemen-elemennya; (2) bahasa dalam legenda menampilkan ciri tersendiri, yaitu merujuk pada kejadian masa lalu. (3) legenda tersusun dari satuan-satuan yang terdiri atas gross constiuent units atau disebut mitem (mythemes) (Endaswara, 2003:111).

Analisis mitos/legenda model LeviStrauss dapat berupa kajian struktural. Apabila bahan kajian hanya satu legenda, peneliti akan mencari struktur perjalanan cerita, tokoh, ideologi tokoh, dan sebagainya. Unsur-unsur struktur intrinsik cerita selanjutnya distrukturkan. Legenda dianggap memiliki pesan tertentu. Si pemberi pesan adalah penulis legenda, yaitu orang-orang dahulu yang menyampaikan pesan kepada generasi terdahulu. Oleh karenanya, pada waktu meneliti harus ada asumsi seakan-akan terjadi komunikasi antara pemberi pesan dan penerima pesan (Endaswara, 2003:113).

Selanjutnya, langkah-langkah yang harus dilakukan dalam analisis legenda adalah sebagai berikut.

1. Merekam, mentrasfer, dan mendokumentasikan legenda jika belum berupa tulisan. Dari legenda lisan tersebut peneliti menyalin ke dalam bentuk tulis.

2. Membaca legenda satu demi satu, kemudian diidentifikasi mitem-mitemnya. Mitem adalah satuan analisis, bisa berupa kata atau kalimat.

3. Pencarian mitem, dapat menggunakan sistem kerja trial and error sampai peneliti menemukan struktur yang sulit tergoyahkan. Maksudnya, sampai menemukan struktur yang dapat mewakili sekian banyak legenda tersebut.

4. Kata atau kalimat yang menjadi mitem tadi dicatat dalam kartu data sesuai perkembangan cerita. Masing-masing kartu akhirnya akan melukiskan sebuah relasi. Mitem-mitem tersebut membentuk bendel relasi bukan berupa relasi yang terpisah.

5. Menyusun mitem-mitem tersebut dalam struktur sitagmatis dan paradigmatis (Endaswara, 2003:114).

\section{METODE PENELITIAN}

Penelitian ini merupakan penelitian kualitatif dengan menggunakan metode deskriptif. Data yang diperoleh akan disajikan dalam bentuk deskriptif sebagai ciri khas penelitian kualitatif. Menurut Ratna (2006: 46-47) metode kualitatif memanfaatkan cara-cara penafsiran dengan menyajikan data dalam bentuk deskripsi. Sumber data penelitian kualitatif dalam ilmu sastra adalah karya, naskah, dan data 
penelitian. Sebagai data formalnya adalah kata-kata, kalimat, dan wacana.

Teknik pengumpulan data yang digunakan adalah studi pustaka untuk mencari bahan kepustakaan sebagai acuan dalam membahas objek.

Selanjutnya, langkah-langkah yang harus dilakukan dalam analisis "Legenda Nisan Berlumur Darah" adalah sebagai berikut. 1) membaca legenda kemudian diidentifikasi mitemmitemnya; 2) pencarian mitem dapat menggunakan sistem kerja trial and error sampai peneliti menemukan struktur yang sulit tergoyahkan. Maksudnya, sampai menemukan struktur yang dapat mewakili legenda tersebut; 3) Kata atau kalimat yang menjadi mitem tadi dicatat dalam kartu data sesuai perkembangan cerita. Masing-masing kartu akhirnya akan melukiskan sebuah relasi. Mitem-mitem tersebut membentuk bendel relasi bukan berupa relasi yang terpisah; 4) Menyusun mitem-mitem tersebut dalam struktur sitagmatis dan paradigmatis (Endaswara, 2003:114).

\section{ANALISIS DAN PEMBAHASAN}

\section{A. Urutan Peristiwa/Alur}

(1) Dahulu kala ada cerita tentang dua kekasih yang mempunyai percintaan yang tragis. Ceritanya sebagai berikut. Mashor adalah pemuda yang bertempat tinggal di desa yang sekarang berada di sekitar Pekauman dan Teluk Selong, Martapura. Mashor berasal dari keluarga yang miskin, tetapi mempunyai pendidikan yang tinggi dan budi akhlaknya tinggi. Dia mempunyai keahlian membaca AlQuran yang sangat indah didengar. Mashor yang miskin ikut bekerja di rumah Fatimah sebagai pembantu. Fatimah merupakan gadis dari keluarga sangat kaya. Mereka tinggal di seberang desa Mashor, mungkin sekarang daerah Kampung Melayu. Orang tuanya merupakan pedagang yang mempunyai hubungan dagang keluar daerah. Terutama daerah Singapura.

(2) Mashor sebagai pembantu mempunyai banyak pekerjaan yang harus dilakukannya, seperti menimba air, memotong kayu, dan lain-lain. Hari demi hari, bulan demi bulan itu saja yang dilakukannya untuk membiayai hidupnya dan orang tuanya. Selama beberapa tahun Mashor bekerja dirumah kaya itu membuat Fatimah secara tidak sadar jatuh cinta kepadanya begitu juga sebaliknya. Tetapi karena adat yang menjaga ketat pertemuan antara perawan dengan bujangan membuat hubungan mereka tidak diketahui oleh keluarga.

(3) Mashor sadar percintaan mereka pasti akan ditentang oleh keluarga Fatimah yang memegang adat keluarga. Mereka hanya akan menikahkan anak gadisnya hanya dengan orang yang sederajat dan mempunyai hubungan keluarga bangsawan dan pasti tentu harus pilihan keluarga. Tetapi Cinta di hati tidak bisa menolaknya. Tidak lama kemudian hubungan mereka mulai diketahui orang tua Fatimah. Betapa marahnya orang tua Fatimah mengetahui hal demikian. Mereka memutuskan untuk menjauhkan 
Mashor dari Fatimah dengan menugaskan Mashor menjaga kebun karet dan ladang keluarga Fatimah yang letaknya di seberang sungai.

(4) Kebun karet ini berada jauh dari rumah Fatimah, menujunya hanya bisa dengan perahu jukung karena melewati sungai yang kecil. Mashor di berikan pondok kecil untuk berteduh dan melakukan kegiatan sehari-hari. Setiap hari dia bekerja merawat kebun karet tersebut.

(5) Setiap ada hasil karet hanya orang suruhan keluarga Fatimah saja yang mengambilnya. Dia tidak diberikan kesempatan untuk ke rumah sang Majikan. Fatimah mengetahui kabar Mashor hanya dengan meminta keterangan acil Ijah, pembantu yang sering mengatarkan beras buat Mashor. Suatu hari ada orang kaya bernama Muhdar yang masih ada hubungan keluarga dengan Fatimah badatang (melamar) ke rumah Fatimah dengan menggunakan satu buah kapal yang sangat besar sesuai dengan derajat kekayaan orang tersebut.

(6) Niat Muhdar disambut baik oleh keluarga Fatimah, mereka sepakat untuk mengadakan perkawinan besar-besaran. Hal ini tidak menjadi beban bagi Muhdar karena kakayaannya. Fatimah sangat menentang niat orang tuanya yang menjodohkannya dengan Muhdar. Dia kenal betul perangai Muhdar. Walaupun kaya tetapi dia tidak mempunyai budi pekerti dan ilmu agama sebaik Mashor. Tetapi dia harus menjalankan dua pilihan yang sangat berat. Di satu sisi dia mempunyai pilihan dan cinta yang diyakininya membawa kebahagian di dunia dan di akhirat, yaitu hidup bersama Mashor. Di satu sisi dia harus mengikuti perintah orang tuanya, dia sadar menyakiti hati orang tua adalah perbuatan yang durhaka.

(7) Fatimah pasrah terhadap perjodohan ini. Perjodohan yang dilandasi oleh harta, hubungan keluarga bukan oleh Cinta. Mashor yang berada jauh tidak mengetahui perjodohan ini. Semuanya yang datang ke gubuk tempat Mashor bekerja selalu menutupinya. Mereka tidak ingin dipecat majikan jika menceritakan hal tersebut.

(8) Akhirnya acara pernikahan di mulai, Muhdar datang dengan beberapa kapal besar dengan membawa mas kawin atau jujuran. Ada kapal yang membawa isi kamar lengkap, ada kapal yang membawa perhiasan emas dan batu permata, ada kapal yang membawa pakaian wanita yang sangat indah-indah. Bagi mereka semua itu hal biasa, karena bisnis dagang keluarga ini ke Singapura berupa batu permata dan kain. Mereka mempunyai banyak pelanggan di Singapura.

(9) Pada zaman tersebut sungai Martapura dipergunakan sebagai jalur perdagangan. Kapal-kapal besar pedagang Martapura sering berangkat membawa barang dagangan ke Pulau Jawa dan Sumatera hingga Singapura dan Malaysia. Sesuai dengan jalur perdagangan dunia antara Malaysia dan pulau Sumatera. Pada malam harinya ketika semua kelelahan. 
Muhdar dan Fatimah tidur di kamar penganten.

(10) Belum sempat malam pertama itu terjadi. Ada musibah terjadi, rumah Fatimah terbakar akibat api dari dapur yang lupa dimatikan. Muhdar, suami Fatimah lari keluar dengan segera tanpa memperdulikan Fatimah. Api semakin membesar, Fatimah terjebak di dalamnya. Mashor yang belum tidur melihat dari kejauhan warna merah di langit yang menadakan kebakaran. Dia yakin kebakaran itu berada di rumah Fatimah.

(11) Tanpa peduli aturan majikannya yang tidak memperbolehkannya mendekati rumah sang majikan. Mashor langsung berlari mengambil jukung. Setelah sampai di rumah Fatimah, dia diberitahu bahwa Fatimah terjebak didalam rumah. Dengan kekuatan Cinta, dia menerobos api dan menemukan Fatimah pingsan karena terlalu banyak menghirup asap. Dia angkat Fatimah melewati api yang besar.

(12) Dengan badannya dia melindungi Fatimah dari api dan kayu rumah yang berjatuhan. Setelah dia bawa keluar Mashor disambut Muhdar dengan merebut Fatimah dari pangkuan Mashor. Dengan demikian Mashor akhirnya mengetahui perkawinan tersebut. Belum sempat dia mendapatkan penjelasan, Mashor pingsan karena terlalu banyak luka bakar yang dialaminya.

(13) Keluarga Fatimah memerintahkan agar Mashor dirawat kembali di gubuk tempatnya bekerja. Keluarga Fatimah menginginkan agar peristiwa kepahlawanan Mashor jangan sampai diketahui Fatimah. Saat subuh tiba, Mashor tidak bisa bertahan lagi. Dia meninggal karena luka yang sangat parah. Setelah sholat dzuhur, dia dimakamkan di daerah perkebunan karet tersebut. Atau tepatnya sekarang berada di desa Tungkaran.

(14) Makam Mashor hanya sederhana dengan nisan ulin seadanya. Untuk mencegah babi hutan menghancur, kuburannya dipagar bambu. Teman-teman Mashor maupun keluarga Fatimah menghadiri pemakaman tersebut. Hanya Fatimah yang tidak ikut karena dia tidak mengetahui tentang kematian Mashor..

(15) Fatimah masih lemah di kamar rumah Muhdar. Dia masih bertanya di dalam hati bagaimana dia bisa selamat, suaminya sendiri meninggalkannya saat kebakaran itu terjadi. Sewaktu malam hari pertanyaan itu diutarakannya pada acil Ijah yang sejak kecil merawatnya. Acil Ijah tahu betul perasaan Fatimah kepada Mashor. Acil Ijah tidak dapat mendustai tuannya yang sejak kecil dia rawat tersebut. Akhirnya dia menceritakan peristiwa yang terjadi pada saat kebakaran itu.

(16) Fatimah yang sangat rindu Mashor akhirnya menanyakan keberadaan Mashor. Dengan sangat hati-hati acil Ijah menceritakan kematian Mashor dan memberitahukan letak kuburannya. Dia berjanji menemani Fatimah besok hari untuk berziarah ke kuburan Mashor. Fatimah Sangat terpukul hatinya mengetahui 
pemuda yang melindungi dan dicintainya telah tiada.

(17) Menangislah Fatimah sejadi-jadinya. Setelah semua orang terlelap tidur, saat pukul 03.00 subuh tanpa sepengetahuan yang lain Fatimah keluar rumah. Dia tidak dapat menyimpan perasaan rindu dan dukanya. Tanpa menunggu siang dia bertekad harus menemukan kuburan Mashor. Dia tidak yakin kekasihnya sudah meninggal jika tidak menemukan kuburannya langsung. Dia menyeberangi sungai Martapura dan berjalan menyusuri jalan setapak. Dia masih ingat letak kebun karet keluarganya ketika ayahnya pernah mengajaknya sewaktu kecil. Malam itu sedang hujan deras, tetapi tidak menyurutkan hati Fatimah untuk menemukan kuburan Mashor. Fatimah tidak merasa gentar karena di dalam hatinya hanya ada satu nama "Mashor".

(18) Setelah tiba di kebun karet keluarganya, Fatimah tanpa sadar dan mungkin karena ilusi yang muncul ditambah obsesinya untuk bertemu mashor. Tiba-tiba Fatimah melihat Mashor berdiri tersenyum kepadanya ditengah rintik hujan. Tanpa berpikir panjang Fatimah berlari ingin memeluk tubuh kekasihnya melepaskan segala kerinduannya. Fatimah menabrak tubuh lelaki itu hingga terjatuh. Tanpa disadarinya pagar yang terbuat dari bambu yang melindungi kuburan Mashor menusuk tubuh Fatimah tepat di dadanya. Darah mengucur dan menetes di atas kubur Mashor. Darah Fatimah melumuri nisan Mashor. Akhirnya, Fatimah meninggal dengan senyum bersama keyakinannya menemukan cintanya. Demikianlah, mitos nisan berlumur darah.

\section{B. Makna Legenda Nisan Berlumur Darah (NBD)}

Berdasarkan teks yang disajikan mengenai "Nisan Berlumur Darah" (NBD), analisis struktural akan didasarkan pada episode-episode. Adapun analisisnya sebagai berikut.

\section{a. Episode pertama (paragraf 1-2)}

Episode pertama ini menceritakan mengenai latar belakang identitas Mashor dan Fatimah. Mashor merupakan seorang pembantu yang bekerja pada keluarga Fatimah. Kehidupan sosial Mashor tentu berbeda dengan Fatimah. Mashor yang seorang pembantu berasal dari keluarga miskin. Sedangkan Fatimah, anak majikannya berasal dari keluarga pedagang kaya raya. Seringnya mereka bertemu menyebabkan benih-benih cinta terjalin.

Dalam cerita, jalinan cinta Mashor dan Fatimah terjalin secara diam-diam tanpa ada yang tahu. Namun, seiring berjalannya waktu akhirnya keluarga Fatimah mengetahui kisah cinta mereka. Perbedaan status sosial merupakan alasan utama, cinta muda mudi itu tidak sampai pelaminan. Mashor yang berakhlak mulia dan memiliki suara merdu ketika mengaji (pengetahuan yang baik dalam agama Islam) dianggap tidak sepadan oleh keluarga Fatimah. Keluarga Fatimah menghendaki calon suami Fatimah haruslah juga kaya raya atau berasal dari keturunan bangsawan. Ini menunjukkan bahwa keluarga 
Fatimah memandang kebahagian berasal dari kekayaan dan keturunan.

Selanjutnya, Mashor diperintahkan untuk mengurus perkebunan karet milik keluarga Fatimah. Perkebunan itu letaknya sangat jauh dari rumah keluarga Fatimah. Mashor melewati sungai kecil dengan perahu kecil menuju gubuk kecil di perkebunan karet itu. Gubuk kecil itulah yang menjadi tempat tinggal Mashor. Namun, Mashor tidak diperkenankan kemana-mana. Setiap bulan, ada suruhan keluarga Fatimah yang mengambil hasil karet dan mengantarkan berbagai keperluan sehari-hari untuk Mashor.

Kontradiktif pandangan mengutamakan harta (matrealisme) dengan mempersoalkan perbedaan sosial pada episode I ini berbanding terbalik dengan kebiasaan masyarakat Banjar. Pandangan mengutamakan harta atau kekayaan ketika memilih menantu dalam masyarakat Banjar (orang Martapura) dianggap sesuatu keliru. Hal tersebut mengingat masyarakat Banjar yang sangat taat pada ajaran Islam. Dalam Islam mengajarkan seseorang untuk mengutama pilihan pendamping hidup atau menantu yang baik pemahamannya tentang Islam. Seseorang yang baik pengetahuannya tentang Islam dianggap akan membawa kepada kebahagiaan hidup baik di dunia maupun di akhirat bagi pasangannya.

Namun, di era modernisasi sekarang ini bukan tidak mungkin pandangan materialisme (mengutamakan harta) menjadi pilihan yang utama. Oleh karenanya, generasi terdahulu mengingatkan melalui cerita rakyat ini. Pandangan mengutamakan harta dengan mempersoalkan status sosial yang berbeda merupakan awal dari suatu bencana. Kejadian yang berakhir tragis tersebut terjadi pada kehidupan Mashor dan Fatimah. Pandangan keluarga Fatimah yang menilai kebahagian seseorang berdasarkan harta atau asal usul keturunan, mendatangkan petaka bagi kehidupan Fatimah (anaknya sendiri).

\section{b. Episode II (paragraf 3--9)}

Episode II (paragraf 3--9) menceritakan tentang dampak terungkapnya kisah cinta antara Fatimah dan Mashor. Akhirnya keluarga Fatimah mencari cara memisahkan Mashor dan Fatimah. Kemudian diputuskan agar Mashor diberi pekerjaan untuk mengurus perkebunan karet yang letaknya jauh dari rumah keluarga Fatimah. Mashor harus menyebrangi sungai kecil dengan perahu kecil menuju gubuk di perkebunan karet. Gubuk kecil itulah selanjutnya yang menjadi tempat tinggal Mashor untuk mengurus perkebunan karet. Mashor tidak diberikan kesempatan meninggalkan perkebunan karet tersebut. Setiap bulan ada suruhan keluarga Fatimah yang datang mengambil panenan karet dan mengantarkan berbagai keperluan hidup Mashor.

Datanglah seorang pemuda bernama Muhran yang kaya raya melamar Fatimah. Melamar dalam istilah masyarakat Banjar disebut badatang. Badatang dilakukan oleh seorang pria ke rumah keluarga perempuan untuk melamarnya. Badatang sudah merupakan pembicaraan resmi, maksudnya biasanya sebelumnya sudah 
ada pembicaraan terdahulu antara si laki-laki tersebut atau orang yang diutus oleh pihak laki-laki ke keluarga perempuan. Pembicaraan itu dimaksudkan untuk menanyakan kepada si perempuan atau keluarga perempuan ada sudah atau belumkah si perempuan memiliki ikatan. Selain itu, ditanyakan juga kira-kira lamaran si laki-laki akan diterima atau tidak. Pembicaraan sebelum badatang ini dinamakan basasuluh. Apabila keluarga perempuan menerima barulah si lakilaki melanjutkan dengan badatang.

Setelah badatang barulah acara pernikahan. Saat pernikahan inilah si laki-laki membawa jujuran atau mas kawin untuk calon istrinya. Seperti halnya dalam legenda ini, diceritakan Muhran membawa jujuran yang banyak untuk Fatimah. Ada kapal yang membawa isi kamar lengkap, ada kapal yang membawa perhiasan emas dan batu permata, dan ada kapal yang membawa pakaian wanita yang sangat indah-indah. Bagi keluarga Muhran hal itu biasa saja karena bisnis dagang keluarga ini ke Singapura berupa batu permata dan kain. Mereka mempunyai banyak pelanggan di Singapura.

Pada zaman tersebut sungai Martapura dipergunakan sebagai jalur perdagangan. Kapal-kapal besar pedagang Martapura sering berangkat membawa barang dagangan ke Pulau Jawa dan Sumatera hingga Singapura dan Malaysia. Sesuai dengan jalur perdagangan dunia antara Malaysia dan pulau Sumatera. Dipergunakannya sungai Martapura sebagai jalur perdagangan menunjukkan kehidupan masyarakat Banjar yang dekat dengan sungai. Sungai juga digunakan sebagai sumber air untuk kebutuhan sehari-hari masyarakat. Hal tersebut menunjukkan bahwa orang Martapura terkenal piawai dalam berdagang. Perdagangan zaman dahulu terutama menggunakan sungai sebagai jalur transfortasi untuk memasarkan dagangan.

Fatimah pada akhirnya menyanggupi untuk menikah dengan Muhran. Fatimah terpaksa mengorbankan perasaan cintanya, demi baktinya kepada orang tuanya. Dia tidak mau menjadi anak durhaka atau katulahan. Kepahamannya kepada ajaran Islam menuntunnya untuk menghormati orang tuanya. Inilah gambaran anak-anak solehah/soleh yang berbakti dan patuh kepada orang tua pada masyarakat Banjar. Pelajaran tersebut yang diajarkan oleh generasi terdahulu kepada para penerusnya.

Dalam legenda NBD ini, keputusan keluarga Fatimah untuk menikahkan anaknya dengan Muhran dianggap keliru. Pernikahan Fatimah dengan Muhran yang berdasarkan pertimbangan harta dan status sosial pada akhirnya mendatangkan petaka bagi Fatimah. Proses pernikahan pada episode II ini banyak menggambarkan berbagai adat istiadat pernikahan pada masyarakat Banjar. Proses pernikahan tersebut juga memuat beragam nilai kehidupan yang dipegang teguh oleh masyarakat Banjar.

\section{c. Episode III (paragraf 10-13)}

Episode III (paragraf 10-13) menceritakan kebakaran di rumah yang ditempati Fatimah dan suaminya. Kebakaran tersebut terjadi usai acara pernikahan. Saat kebakaran terjadi, Muhran terbangun kemudian langsung 
lari keluar rumah tanpa mempedulikan Fatimah. Fatimah yang tertidur pulas tidak menyadari kebakaran tersebut.

Berbeda dengan Muhran, di seberang sungai kecil Mashor yang melihat kilatan api besar segera menuju tempat api. Mashor berfirasat kebakaran tersebut terjadi di rumah Fatimah. Segera setelah mengetahui Fatimah masih berada di dalam rumah, ia menerobos api tanpa peduli keselamatan dirinya. Fatimah selamat, sementara itu Mashor terluka bakar yang sangat parah.

Episode III ini terdapat kontradiktif antara Mashor dan Muhran. Mashor si pemuda miskin dengan akhlak dan pengetahuan agama yang baik. Sebaliknya, Muhran si pemuda kaya raya dengan akhlak dan pengetahuan agama yang tidak sebaik Mashor. Mashor yang tidak direstui cintanya untuk menikahi Fatimah. Sedangkan, Muhran yang kemudian dipilih sebagai pendamping Fatimah. Pada episode III ini dibuktikan jika memilih suami/menantu pilihan utama haruslah berdasarkan kebaikan akhlak dan pengetahuan agama sesuai tuntunan Islam. Kreteria itulah yang akan membawa kebahagiaan. Hal tersebut menunjukkan kekeliruan para orang tua bila memaksakan kehendak agar anaknya menikah dengan laki-laki yang hartawan. Legenda ini mengingatkan para orang tua untuk mengingat perintah agama untuk mengutamakan pilihan kepada yang baik agama dan akhlaknya.

\section{d. Episode IV (paragraf 14-18)}

Episode IV (paragraf 14-18) menceritakan akhir tragis dari kisah kasih yang tak sampai. Mashor yang terluka bakar sangat parah pada akhirnya meninggal dunia. Mashor dikuburkan di perkebunan karet tempatnya bekerja. Kuburannya bernisankan kayu ulin berpagar buluh atau bambu tajam. Meninggalnya Mashor tidak diketahui oleh Fatimah. Setelah acil atau bibi Ijah menceritakan, barulah Fatimah mengetahui kematian Mashor. Fatimah sangat sedih hatinya mengetahui Mashor telah tiada.

Fatimah nekad pergi ke makam Mashor pada malam hari, setelah semua orang di rumahnya tertidur. Ingatan masa kecil tentang kebun karet ayahnya itu menuntun Fatimah menuju makam Mashor. Bayangan Mashor berkelebat dalam ingatannya. Tiba-tiba Fatimah melihat Mashor berdiri tersenyum kepadanya di tengah rintik hujan. Tanpa berpikir panjang Fatimah berlari ingin memeluk tubuh kekasihnya untuk melepaskan segala kerinduannya. Fatimah menabrak tubuh lelaki itu hingga terjatuh. Tanpa disadarinya, pagar yang terbuat dari bambu yang melindungi kuburan Mashor menusuk tubuh Fatimah tepat di dadanya. Darah mengucur dan menetes di atas kubur Mashor. Darah Fatimah melumuri nisan Mashor. Akhirnya, Fatimah meninggal dengan senyum bersama keyakinannya menemukan cintanya. Darah yang menggenang di nisan menyebabkan legenda cerita ini dikenal dengan "nisan berlumur darah".

Episode IV ini menceritakan akhir percintaan tragis Fatimah dan Mashor. Cinta pasangan muda mudi ini kandas 
karena tidak mendapat restu orang tua Fatimah. Kemiskinan Mashor itulah penyebab penolakan orang tua Fatimah. Orang tua Fatimah memilih Muhran yang kaya raya. Bagi orang tua Fatimah, orang kaya haruslah bersanding dengan orang kaya atau bangsawan. Fatimah gadis anak orang kaya tak pantas bersanding dengan orang miskin. Dalam hal ini, ukuran kebahagian bagi orang tua Fatimah diukur dari banyaknya harta yang dimiliki. Pandangan orang tua Fatimah sebenarnya kurang sesuai dengan tuntunan agama Islam yang mengajarkan umatnya untuk mengutamakan pilihan terhadap calon pendamping hidup berdasarkan baik tidaknya pemahaman agama.

Episode IV inilah pembuktian kebenaran dari perintah agama. Menyandarkan pilihan kebahagian berumah tangga sebenarnya bukan berdasarkan harta atau kekayaan, tetapi kepada kebaikan pemahaman agama yang dimiliki seseorang. Mashor yang berpengetahuan agama baik, rela mengorbankan jiwanya demi menyelamatkan nyawa Fatimah. Sedangkan Muhran memilih menyelamatkan diri sendiri. Sebagai seorang suami, Muhran telah mengabaikan tanggung jawabnya menyelamatkan istrinya. Akhir cerita, pilihan orang tua Fatimah terhadap jodoh putrinya mendatangkan kepedihan untuk putrinya sendiri. Putri kesayangannya begitu menderita kehilangan Mashor sang kekasih hati yang baik hati. Orang tua Fatimah harus membayar mahal dengan kematian putrinya yang bersimbah darah pada kuburan Mashor.

\section{PENUTUP}

Berdasarkan analisis di atas, Legenda Nisan Berlumur Darah sebagai sebuah legenda yang menyimpan simbolsimbol yang dapat dimaknai secara tidak langsung mengenai prinsip hidup orang Martapura. Legenda ini menunjukkan bahwa prinsip-prinsip kebiasaan hidup yang berpegang pada aturan agama akan membawa kebaikan dan kebahagian hidup.

Semoga penelitian sederhana ini, menumbuhkan kesadaran pentingnya melestarikan tradisi lisan Banjar dalam hal ini cerita rakyat.

\section{DAFTAR PUSTAKA}

Danandjaja, James. 1982. Folklor Indonesia. Jakarta.Grafiti

Daud, Alfani. 1997. Islam dan Masyarakat Banjar: Deskripsi dan Analisa Kebudayaan Banjar. Jakarta: PT Raja Grasindo Persada.

Endaswara, Suwardi. 2003. Metodelogi Penelitian Sastra. Yogyakarta: Pustaka Widyatama.

Ideham, Suriansyah. M, dkk. 2005. Urang Banjar dan Kebudayaannya. Banjarmasin: PT. Grafika Wangi Kalimantan. 
Memaknai Nisan Berlumur Darah (Analisis Strukturalisme Levi-strauss) (Sri Wahyu Nengsih)

Ismail, Abdurachman. 1980. Cerita Rakyat Kalimantan Selatan. Jakarta: Departemen Pendidikan dan Kebudayaan.

Moleong, Lexy J. 2002. Metodologi Penelitian Kualitatif. Bandung. PT. Rosda.

Prabowo, Dhanu Priyo. 2015. “Makna Mitos Asal Nama Kota Banyuwangi: Sebuah Analisis Strukturalisme Levi-Strauss". Dalam Jurnal Ilmiah.

Rahman, Jajuli. 2009. Legenda Nisan Berlumur Darah. (Sumber:Jufey17.blogspot.com/2009/04) diunduh 1Agustus 2016.

Ratna, Nyoman Kutha. 2006. Teori, Metode, dan Teknik Penelitian Sastra. Yogyakarta: Pusat Pelajar.

Taum, Yoseph Yapi. 2011. Studi Sastra Lisan: Sejarah, Teori, Metode, dan Pendekatan Disertasi Contoh dan Penerapannya. Yogyakarta: Lamera. 